\title{
A Study of the Influence of the Surrounding Gas on the Plasma Jet and Coating Quality during Plasma Spraying
}

\author{
T. Liu ${ }^{1}$, A. Ansar and J. Arnold \\ Deutsche Forschungsanstalt für Luft- und Raumfahrt (DLR), Institut für Technische \\ Thermodynamik, Pfaffenwaldring 38-40, D-70569 Stuttgart, Germany
}

\begin{abstract}
Coating quality is affected by arc and plume instabilities during plasma spraying. In closed chamber plasma spraying, gradual drift is one of the intermediate instabilities, which is mainly due to the electrode erosion. This work focuses on the source of the gradual drift of the plasma jet and the influence on coating quality. The ambient state inside the chamber was controlled by a ventilation system and a vacuum system. The variation in the plasma jet was observed by a particle flux image (PFI) device based on a CCD camera. The optical spectrum of the plasma plume was measured and analyzed through an optical spectrometer. The results indicated that the addition of hydrogen to plasma gas induced the change in the plasma jet length and width with changing rates depending on the chamber state and the ventilation power. With poor ventilation, the intensity of $\mathrm{H}_{\alpha}$ emission was found to become gradually stronger while $\mathrm{H}_{\beta}$ and $\mathrm{H}_{\gamma}$ were found to become weaker. On closing the chamber and remaining enough ventilation power, it was observed that the ambient gas slowly turned red. Simultaneously, the coating weight and thickness were slightly decreased meanwhile the porosity ratio was obviously increased. The red ambient gas has been proved to be able to acidify the city water with $\mathrm{pH}$ value decreased from 7 to $1 \sim 3$. Without hydrogen, the plasma jet was found to be stable without reddening and variation, but the plasma enthalpy was unfortunately low.
\end{abstract}

Keywords: plasma spray; reddening phenomenon; plasma stability; emission intensity; coating quality

\footnotetext{
${ }^{1}$ Corresponding author, Dr. Taikai Liu, Tel: +49 (0)711 6862 316, Fax: +49 (0)711 6862 747; E-Mail: taikai.liu@dlr.de.
} 


\section{Introduction}

Plasma spray is widely used to produce coatings to improve surface properties for application in demanding environments [1-2], such as thermal barrier coatings in gas turbines [3-5], anticorrosion coatings in marine and chemical industries [6-8], anti-friction coatings [9-11], etc. The relation between coating properties and the operating parameters has been extensively studied through experimental methods and numerical simulations [12-17] for the possibility to tailor the properties of coating. Nowadays, it is still a challenge to precisely control the coating properties, which is a major drawback of plasma spray. Much research in recent years has focused on the instabilities of process which randomize the performance of coating in some degree and can scarcely be avoided [18-19].

It is generally accepted that the source of such kind of instabilities is numerous: fluctuations of arc voltage, plasma gas composition, variations in powder feeding, entrainment of the surrounding gas, etc. [18-23]. Regarding the time scale, the instabilities can be imaginarily classified into two categories: high-frequency fluctuations, denoted as "uncertainty" which mainly results from the unstable discharge of arc [18] (Fig. 1(b)); and long-term fluctuations, denoted as "drift" which is usually considered as the result of electrode erosions [20-21] (Fig. 1(c)). The high-frequency instability occurs in time intervals with a magnitude of milliseconds, as mentioned by Herlei J.V. [20]. The "drift” causes instabilities in the range of from minutes to hours [21-22]. A lot of efforts have been put on the high-frequency instabilities [18-20], while only a few researches focused on the "drift” [20-21]. The arc voltage presents a gradual decrease with duration over dozens of hours owing to the existence of "drift" [21]. Some works have been dedicated as a solution of the gradual decrease that parametric compensation can be realized to maintain coating properties according to the results of numerical simulation, for example, the artificial neural networks [13-14, 24]. 

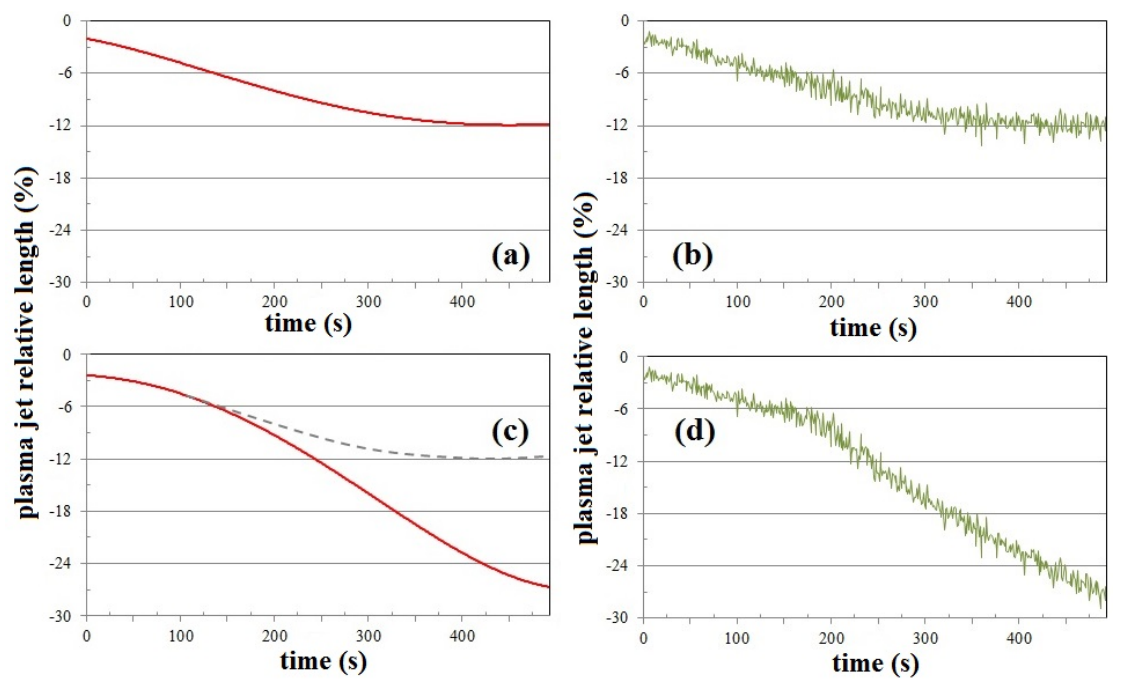

Fig. 1components of a measurement in plasma spray

Unfortunately, these compensations do not always guarantee good properties of coating since there is another important source of the "drift": the entrainment of surrounding gas in the plasma jet [1-2, 25-27]. Hot plasma gas penetrates into the cold environment, leading to interactions between the hot gas and the cold gas. Eddies formed around the plume can entrain the cold surrounding gas in and draw it towards the plasma core through the circulation of the mixed gas. By doing so the plasma plume heats up and accelerates the entrained gas which sometimes gets ionized depending on its radial displacement and its composition [1-2]. In parallel, plasma gas from the nozzle exit flows in the axial direction with radial expansion which results in a dilution. Consequently, the plasma gas quickly slows down; its enthalpy is also dramatically reduced; and its composition changes along the spray direction as well as radially. Moreover, the chamber is gradually filled up by the depleted plasma gas that subsequently causes decrease in plasma temperature and velocity.

Therefore, the aim of this work is to understand the influence of the "drift", caused by gas entrainment, on plasma process and on coating properties. For doing this, the plasma plume was watched by a camera to detect the luminosity change and by an optic sensor to identify the variation in intensity of interesting emission lines. The spraying chamber was controlled via a sealing cover to be opened/closed to air; and with an integrated ventilation pump / vacuum pump, it was able to be maintained in the state of vacuum/air-filled/mixture-gasfilled/depleted-gas-filled. Hence, it is possible to spray coatings in ambient condition with evident difference. As a reasonable characterizing method, the porosity ratio of coating was 
estimated based on the optic micrograph to identify the influence of ambient gas on coating properties.

\section{Methodology and Experimental installation}

\subsection{Plasma jet}

For better understanding the interaction between the hot plasma gas and the cold surrounding gas, it is worth to have some conception about the behavior of electrons and ions in the plasma jet. In general, the generation of plasma can be hypothetically considered as a twostep procedure: ionization and recombination. When crossing the plasma core, the influent plasma gas is mostly dissociated/excited/ionized [28-29] to ions and electrons owing to the high energy of the pulsing arc between the cathode and the anode. In such a way, a part of the electrical power is absorbed by electrons as ionizing energy to jump from current energy level to a higher level or even to escape from the atomic nucleus. In consequence, many kinds of ions are simultaneously generated, e.g., $\mathrm{H}, \mathrm{H}^{+}, \mathrm{H}_{2}{ }^{+}, \mathrm{H}_{3}{ }^{+}, \mathrm{ArH}^{+}, \mathrm{Ar}^{+}, \mathrm{Ar}^{2+}, \mathrm{Ar}^{*}[28,30,31]$ in argon-hydrogen plasma. The temperature of the excited electron is often in order of magnitude of $10^{3} \sim 10^{5} \mathrm{~K}$ [32-33].

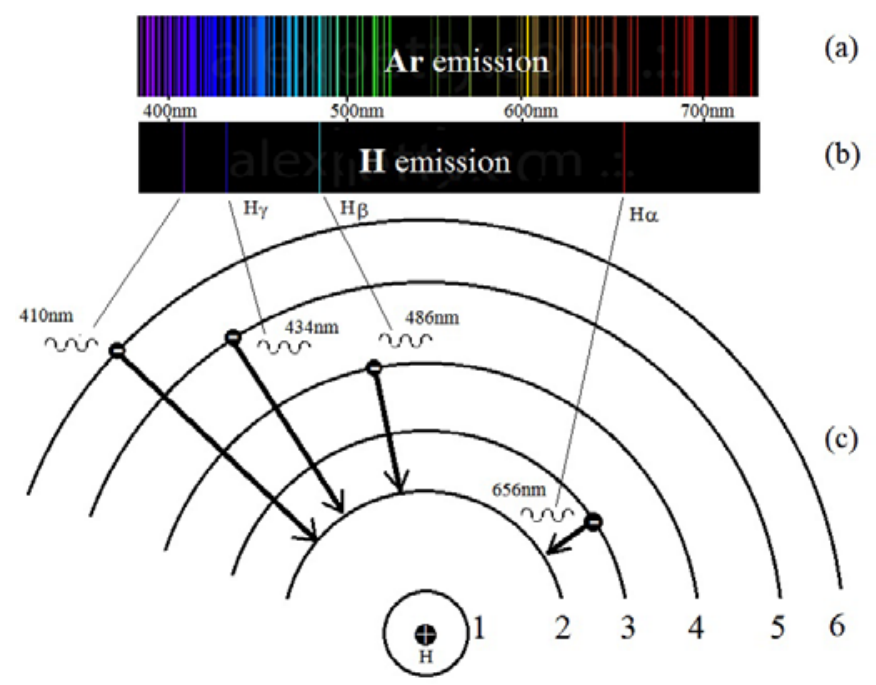

Fig. 2 emission spectrum of hydrogen and the recombination

Secondly, the recombination, it occurs everywhere in the plasma core and plume. That the electrons are recaptured/exchanged by ions, by neutral atoms, or by entrained gas to form a 
stable state releasing energy by means of radiation with certain wavelengths [28-29]. As shown in Fig. 2 (c), when charged with certain energy, electron can jump from ground state to a higher level, such as level 2, level 3 ... level 6, or even higher. The lifetime of such an excited electron is normally very short, e.g., hydrogen molecular with electron in level 3 expires in about $10^{-8} \mathrm{~s}$ [32]. By dropping down to a lower energy level, the excess energy of electron is released in the form of electromagnetic wave, which can be eliminated by ambient gas or absorbed by other species. According to the emission spectrum of Hydrogen (see Fig. 2 (b)), four emission lines can be detected in the visible spectrum with different wavelengths which are assigned as: level $3 \rightarrow$ level 2 emits red light (656 nm); level $4 \rightarrow$ level 2 emits cyan light (486 nm), level $5 \rightarrow$ level 2 emits dark-blue light (434 nm); level $6 \rightarrow$ level 2 emits violet light $(410 \mathrm{~nm})$. In the other hand, the emission line spectrum of Argon is much sundry than that of hydrogen that makes it unsuitable for the purpose of this work. Therefore, by detecting the intensity of hydrogen emission lines, it is possible to savvy the state of process in argon-hydrogen plasma.

\subsection{State of the spraying chamber}

The state of the spraying chamber is also a non-negligible factor to the final coating properties. The chamber was able to be completely closed or opened to air, which results obvious difference in accumulating rate of the depleted gas. As an internal state of the spraying chamber, the composition of ambient gas can be totally different from the original point after some time of spraying depending on the accumulation rate.

As mentioned above, the species produced in $\mathrm{Ar}-\mathrm{H}_{2}$ plasma, which is subsequently released to the ambient and cooled down as a new component of the ambient gas, are denoted as the depleted gas. In theory, with duration long enough, the spraying chamber (not directly opened to air) will be fully filled up by the depleted gas. As a result, even in industrial application with adequate ventilation system, the state of spraying chamber is unavoidably derived from the original state after several hours of spraying.

In another word, the ventilation system works under pressure equilibrium between the atmosphere and the spraying chamber (with dynamic pressure of the pump). All components of the ambient gas are supposed to be equally drawn by the pump. The fraction of air in ambient gas obviously cannot increase due to the enclosure of the spraying chamber; conversely, the fraction of the depleted plasma gas continuously increases during the spraying process. As an inference, the volume of chamber will be finally filled up by the depleted 
plasma gas. Resultantly, the accumulation of depleted gas in the spraying chamber is unavoidable in $\mathrm{Ar}-\mathrm{H}_{2}$ plasma. The accumulating rate depends on the volume of the spraying chamber and the ventilation power. The accumulation of the depleted gas is supposed to evidently affect coating properties when its partial pressure is non-negligibly high.

In industry, the spraying chamber is often coupled with sufficient ventilation capability that it is able to maintain a rather low accumulating rate of the depleted gas. On the other hand, there are many lab-level applications for fundamental research, which is unable neither to keep a big enough chamber, nor to have an adequate ventilation system. Therefore, for lab-level applications the influence of the depleted gas on coating properties is more critical than in industry. This drew the attention to control the spraying chamber state by adjusting the ventilation power for finally achieving different accumulating rate of the depleted gas.

\subsection{Experimental installations}

This work was carried out in a sealable chamber which was designed for vacuum plasma spraying (Fig. 3(a)). The chamber was able to be controlled by a vacuum pump or/and a ventilation system for achieving different spraying conditions. Consequently, the pressure of the spraying chamber was able either to be maintained as low as $6000 \mathrm{~Pa}$ for vacuum spray, or to be kept at $1 \mathrm{~atm}$. for atmospheric plasma spray (APS) with adjustable power of ventilation between 0 and $100 \%$. Inside the chamber, a F4-VB type torch with an internal anode aperture of $6 \mathrm{~mm}$ was installed on an X-Y movement system (Fig. 3(b)). The torch was water cooled with a flux automatically adjusted between $12 \mathrm{~L} / \mathrm{min}$ and $15 \mathrm{~L} / \mathrm{min}$ for maintaining the temperature of the back-flow water below $50{ }^{\circ} \mathrm{C}$. The feedstock used in this work was yttria-stabilized zirconia (8YSZ, $\left(\mathrm{ZrO}_{2}\right)_{92}\left(\mathrm{Y}_{2} \mathrm{O}_{3}\right)_{8}$, Metco 6613) with size of -25 $\mu \mathrm{m} / 5 \mu \mathrm{m}\left(\mathrm{d}_{90} / \mathrm{d}_{10}\right)$ ((see Fig. 4), which was perpendicularly fed through an injector with 1.8 $\mathrm{mm}$ internal diameter being installed $3 \mathrm{~mm}$ upstream to the nozzle exit. The flow rate of the carrier gas, Argon, was carefully optimized to expose powder in the plasma core region as much as possible. Crofer $22 \mathrm{H}(\mathrm{Fe}+22$ wt.-\% $\mathrm{Cr}$ ) sheets with dimension of $47 \mathrm{~mm} \mathrm{x} 47 \mathrm{~mm} \mathrm{x}$ $0.5 \mathrm{~mm}$ were chosen to serve as substrate which was held by a 304L steel plate $(600 \mathrm{~mm} \mathrm{x}$ $600 \mathrm{~mm} \times 20 \mathrm{~mm}$ ) for protecting samples from suffering high temperature. Substrate temperature was measured with a thermocouple fixed at its back center for avoiding influence from the plasma jet and without losing too much contact with the steel plate. In parallel, at the backside of the steel plate (sample holder), a thermocouple was fixed and planted at the center for detecting thermal state of the sample holder. The installation of plasma luminosity and emission detecting devices will be detailed later in following sections. 


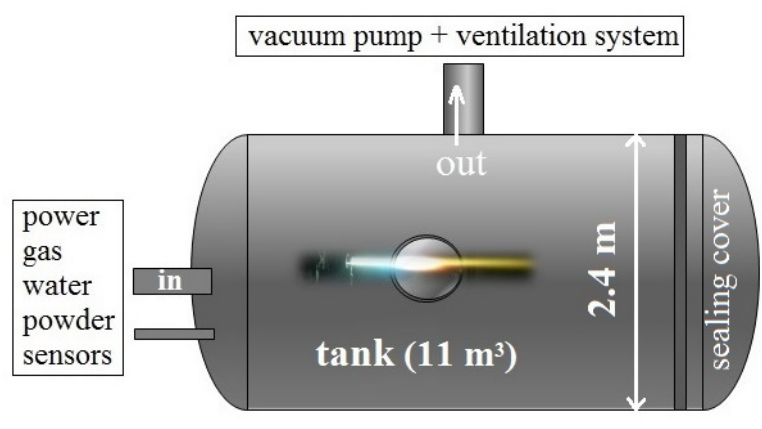

(a)

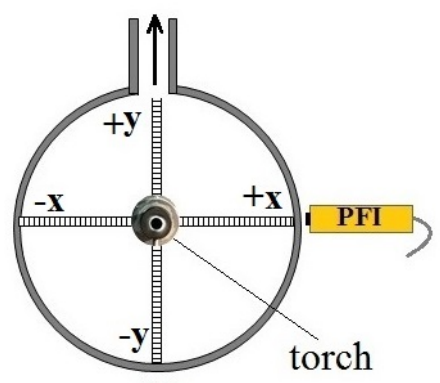

(b)

Fig. 3 experimental installation for plasma spraying process

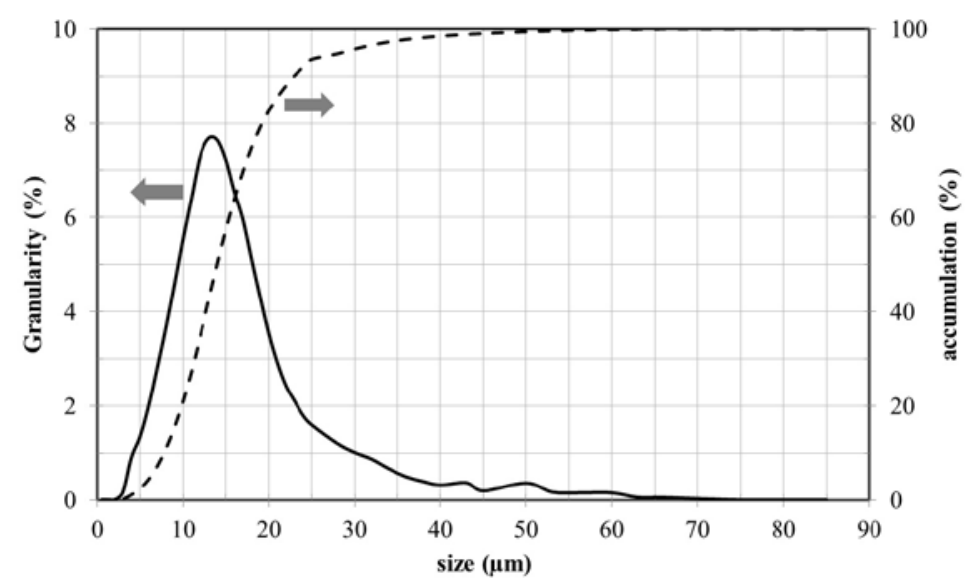

Fig. 4 granularity of $8 Y S Z$ powder

Accordingly, the operating parameters were listed in Tab. 1 with two categories: with powder feeding for obtaining coatings and without powder feeding for observing the behavior of plasma jet. As presented in Tab. 1, four samples were equally obtained for each case of case 1 , case 2, case 3 and case 4 at different time indicated in Tab. 2 with spraying distance of 120 mm for APS cases and $200 \mathrm{~mm}$ for VPS case; while only data about the variation of plasma jet was collected in case 5 and case 6 which were carried out to check the effect of operating parameters on the plasma jet by means of adjusting the state of the sealing cover and the operating parameters. The operating details of case 6 were given as below:

- OP 6(a): chamber closed, $\mathrm{H}_{2}=3 \mathrm{~L} / \mathrm{min}$, no ventilation;

- OP 6(b): chamber completely opened, $\mathrm{H}_{2}=3 \mathrm{~L} / \mathrm{min}$, no ventilation; 
- OP 6(c): chamber opened with a gap of $5 \mathrm{~cm}$ between the sealing cover and the tank, $\mathrm{H}_{2}=3 \mathrm{~L} / \mathrm{min}$, no ventilation;

- OP 6(d1): chamber completely opened, $\mathrm{H}_{2}=3 \mathrm{~L} / \mathrm{min}$, no ventilation;

- OP 6(d2): chamber completely opened, $\mathrm{H}_{2}=0 \mathrm{~L} / \mathrm{min}$, no ventilation;

- OP 6(d3): chamber completely opened, $\mathrm{H}_{2}=5 \mathrm{~L} / \mathrm{min}$, no ventilation;

- OP 6(d4): chamber completely opened, $\mathrm{H}_{2}=2 \mathrm{~L} / \mathrm{min}$, no ventilation;

- OP 6(d5): chamber completely opened, $\mathrm{H}_{2}=1 \mathrm{~L} / \mathrm{min}$, no ventilation;

- OP 6(d6): chamber completely opened, $\mathrm{H}_{2}=3 \mathrm{~L} / \mathrm{min}$, no ventilation;

- OP 6(e): chamber closed, $\mathrm{H}_{2}=3 \mathrm{~L} / \mathrm{min}$, no ventilation;

For each case, the intensities of emission lines of hydrogen in the visible spectrum were measured at different times. Moreover, for checking any possible change in the color of the gas inside the spraying chamber, photos were captured after each measurement of the emission intensity by temporarily switching off the plasma (see Tab. 2).

Table 1 Operating Parameters and details for each case

\begin{tabular}{ccccccccc}
\hline Case & $\mathrm{I}(\mathrm{A})$ & $\begin{array}{c}\mathrm{Ar} \\
(\mathrm{SLM})\end{array}$ & $\begin{array}{c}\mathrm{H}_{2} \\
(\mathrm{SLM})\end{array}$ & $\begin{array}{c}\mathrm{P}_{\text {chamber }} \\
(\mathrm{x} 100 \mathrm{~Pa})\end{array}$ & $\begin{array}{c}\text { chamber } \\
\text { state }\end{array}$ & $\begin{array}{c}\text { ventilation } \\
\text { power (\%) }\end{array}$ & coating & $\begin{array}{c}\text { duration } \\
\text { (min) }\end{array}$ \\
\hline $1^{*}$ & 600 & 45 & 3 & 942 & close & 0 & Yes & 24 \\
2 & 600 & 45 & 3 & 942 & open & 90 & Yes & 38 \\
3 & 600 & 45 & 3 & 942 & close & 60,20 & Yes & 41 \\
4 & 600 & 45 & 3 & 70 & close & vacuum & Yes & 53 \\
5 & 600 & 45 & 0 & 942 & close & 0 & No & 30 \\
6 & 600 & 45 & $0,1,2,5$ & 942 & close, open & 0 & No & 46 \\
\hline
\end{tabular}

*: the plasma jet was watched through a camera fixed outside the chamber

Table 2 procedure for sample spraying and photo capturing

\begin{tabular}{ccccccccc}
\hline & coat. 1 & action & coat. 2 & action & coat. 3 & action & coat. 4 & action \\
\hline case 1 & $1^{\text {st }}$ min & stop, photo & $5^{\text {th }}$ min & stop, photo & $13^{\text {th }}$ min & stop, photo & $21^{\text {th }}$ min & stop, photo \\
case 2 & $5^{\text {th }}$ min & stop, photo & $15^{\text {th }}$ min & stop, photo & $24^{\text {th }}$ min & stop, photo & $34^{\text {th }}$ min & stop, photo \\
case 3 & $7^{\text {th }}$ min & stop, photo & $18^{\text {th }}$ min & stop, photo & $28^{\text {th }}$ min & stop, photo & $37^{\text {th }}$ min & stop, photo \\
case 4 & $10^{\text {th }}$ min & stop, photo & $24^{\text {th }}$ min & stop, photo & $39^{\text {th }}$ min & stop, photo & $49^{\text {th }}$ min & stop, photo \\
\hline
\end{tabular}




\subsection{Ellipse diagnosis with PFI}

It is generally accepted that the plasma spraying process can be characterized by the plasma plume luminosity. It implies that a change of operating parameters can directly affect the plasma jet [34-35]. Thus, it gives possibility to reasonably detect the "drift” only by observing and quantifying the change of the plasma jet. Accordingly, a commercial device, particle flux imaging (PFI, Zierhut Messtechnik GmbH, München, Germany), was successfully developed and widely used for online diagnosis, which is the reason why PFI was employed in this work. The main component of the PFI is an integrated CCD camera covered by a metallic housing for preventing any possible damage and dust. Before diagnosing, the camera was firmly installed outside the chamber focusing on the plasma jet through a glass-sealed window (see Fig. 2 and Fig. 5). Pictures of the plasma jet and the particles stream (see Fig. 6(a)) were converted into grayscale images (see Fig. 6(b)) and simplified into two ellipses, left ellipse and right ellipse for plasma jet and particles stream respectively. Each ellipse was characterized with five variables: the central position of the ellipse (X, Y), the major diameter $(a)$, the minor diameter $(b)$ and the tilting angle $(\theta)$ between the horizontal axis and the major diameter (see Fig. 6(c)). For estimating the variation of each variable, a graphic reference must be firstly defined before the spraying procedure once the process started to be stable. In consequence, the calculated variations of the five variables could be positive, negative or zero, which indicates an increase, a decrease and no change respectively; and all results were continuously saved during the diagnosis. Owing to the high instability of the particle stream induced by the large fluctuation in the powder feeding [36], only the left ellipse (plasma jet) was concerned and considered in this work and thus these relative variables were marked as: a_l, b_l... (“l” = "left”). 


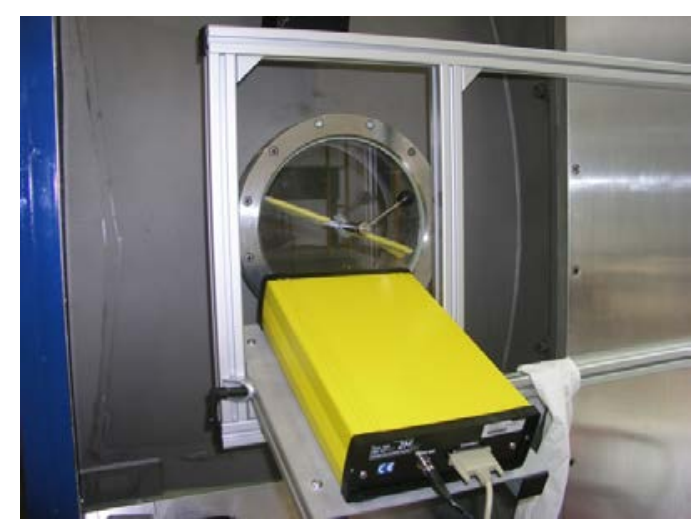

Fig. 5 Installation of PFI: standing outside the chamber and watching the torch via a window with glass sealing (a)

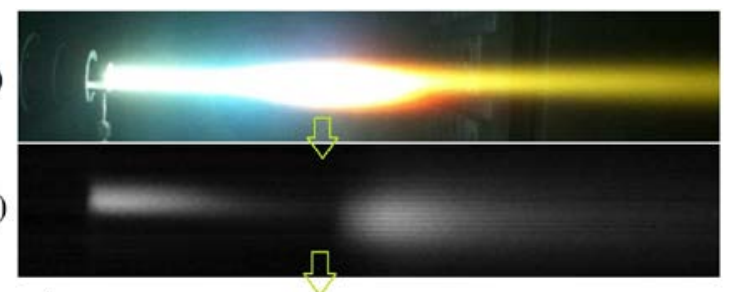

(c)

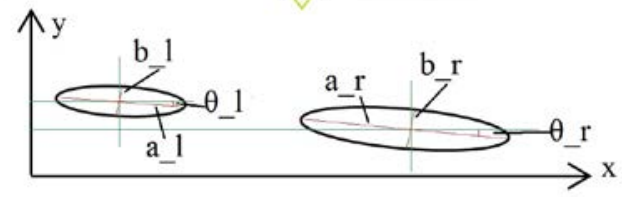

Fig. 6 Image of PFI diagnostics: (a) plasma jet and particle stream, (b) grayed plasma jet and particle stream, (c) characteristics of the ellipses

\subsection{Emission spectrum diagnosis with AOS}

The emission spectrum of the plasma jet was captured by a commercial apparatus, AcoustoOptical Spectrometer 4 (AOS 4, IFU GmbH, Chemnitz, Germany), which is able to record the luminosity of radiated lines with selected wavelengths. The AOS 4 consists of an optical head for capturing the luminous signal and a computer with integrated module for signal selecting, gaining and post treatment. In this work, the optical head of AOS 4 was firmly fixed on the top of the torch (see Fig. 7) with different tilting angles for VPS case and APS cases. That the optical head focused at the plasma plume with a distance of $200 \mathrm{~mm}$ away from the torch exit in VPS process, while the focusing distance was adapted to be $120 \mathrm{~mm}$ in the APS process. For avoiding overexposure, the focal point of the optical head was manually deviated $1 \mathrm{~cm}$ away from the central line of the plasma plume for APS cases and $2 \mathrm{~cm}$ for VPS case. As a consequence, three emission lines of hydrogen $\left(\mathrm{H}_{\alpha}=656 \mathrm{~nm}, \mathrm{H}_{\beta}=486 \mathrm{~nm}\right.$ and $\left.\mathrm{H}_{\gamma}=434 \mathrm{~nm}\right)$ were clearly outstood from the background while leaving the emission line of $410 \mathrm{~nm}$ being covered by the noise [30, 37-38]. Moreover, for diminishing the noise from the in-flight particles, only the data collected with powder feeding off was considered to be valid. 


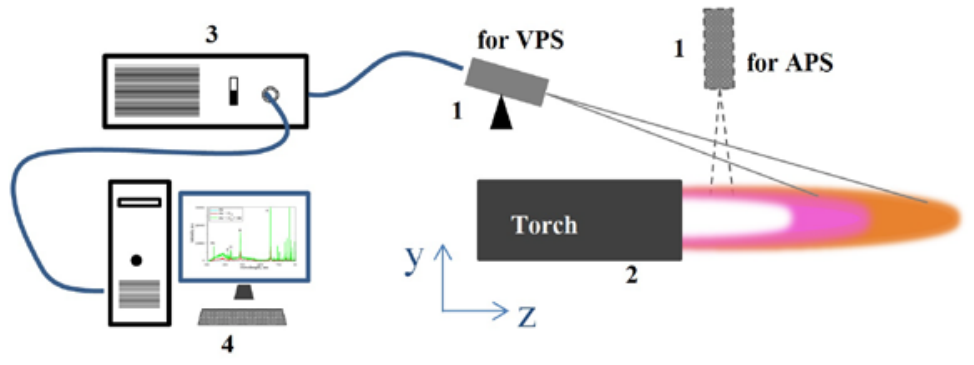

Fig. 7 Installation of Optic Spectrum: 1 - optic sensors (different positions for APS and VPS); 2 - plasma torch and plasma jet; 3 - AOS device (PMT inside); 4 - user interface

\section{Results and discussions}

\section{1 samples preparation}

Totally, 16 substrates were prepared and previously cleaned with propanol and then sandblasted for enhancing the adhesion between coating and substrate. In each case, four substrates were placed in one column at 4 different rows and marked from top to the bottom as sample 1, sample 2, sample 3 and sample 4 respectively. The duration for completing one coating was about 3 mins, which was immediately followed by a short stop of plasma for capturing a photo of the ambient gas with procedure indicated in Tab. 2. All samples were deposited 10 layers with $5 \mathrm{~mm}$ interval between two passes; and the most favorite velocity of torch was $400 \mathrm{~mm} / \mathrm{s}$ with a moderate powder feeding rate of $15 \mathrm{~g} / \mathrm{min}$.

\subsection{The reddening of ambient gas and the variation in plasma jet}

Several photos of the plasma jet were taken in case 1 at different times via the glass-sealed windows with a protecting filter when powder feeding was temporarily switched off. As shown in Fig. 8, an obvious decrease in length of the plasma jet was found. That at the beginning of the process the plasma jet length was roughly $45 \mathrm{~mm}$; then 100 seconds later the length was reduced by $8.5 \mathrm{~mm}$ to $36.5 \mathrm{~mm}$. Meanwhile, the width of plasma jet was slightly increased from $8.2 \mathrm{~mm}$ to $8.6 \mathrm{~mm}$. And hereafter, the plasma jet fell into a stable state after about 10 minutes with $28 \mathrm{~mm}$ length and $8.6 \mathrm{~mm}$ width. 


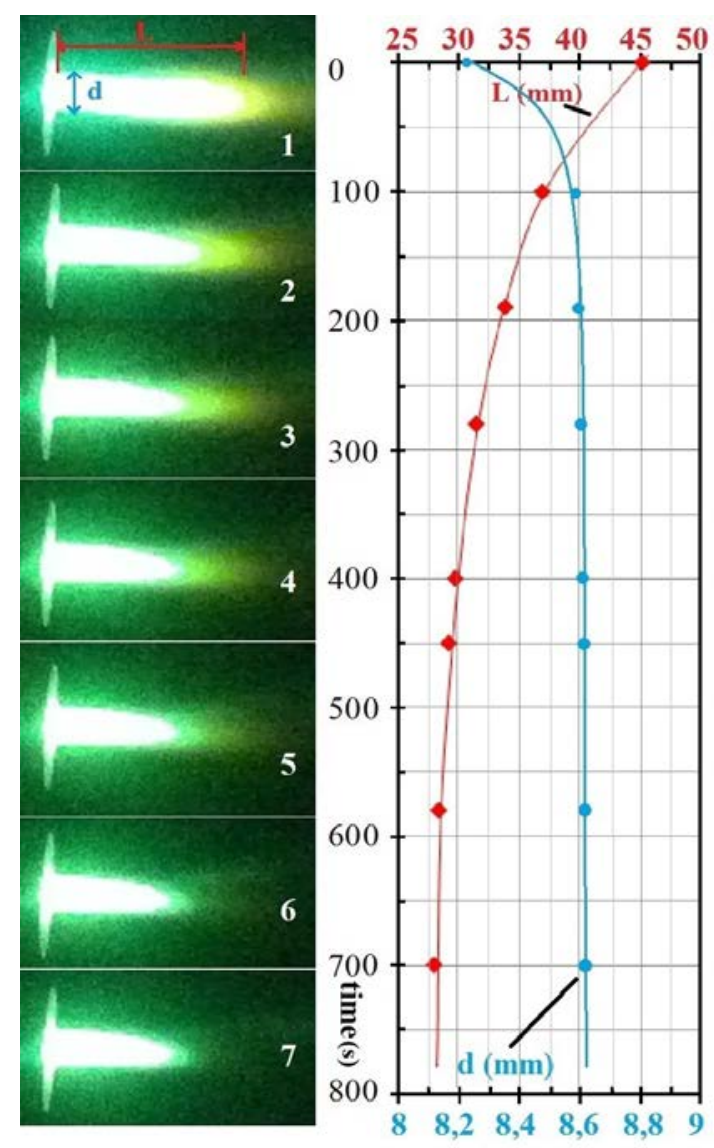

Fig. 8 Variation of plasma plume (length and width) with time elapsing

In parallel, an interesting phenomenon was observed that the color of the ambient gas was being reddened during the process. As presented in Fig. 9, five photos were equally taken after a short stop of the plasma at different times. That the gas color inside the chamber turned to orange from normal white in 9 minutes, then to red after another 9 minutes, and finally turned to scarlet in 24 minutes. Because of the strongly scarlet color of the ambient gas which almost extinguished the plasma, case 1 was resultantly stopped and followed by a pumping action. By switching on the vacuum pump, the gas color visibly faded and turned from scarlet at $94200 \mathrm{~Pa}$ to red at $70000 \mathrm{~Pa}$, to yellow at $20000 \mathrm{~Pa}$ and to normal white at $2000 \mathrm{~Pa}$. Equally, without any operation, the gas color was also able to evidently fade after about 30 minutes and turn to normal white in 2 hours.

For understanding the reason of the reddening phenomenon of the ambient gas, a hypothesis may be proposed that the accumulation of the depleted plasma gas in the spraying chamber induced some change in the ambient gas. Most probably due to the disequilibrium between the ionization/reionization and the recombination of hydrogen, the chamber was gradually 
filled up by the depleted gas (mainly excited hydrogen ions) and became more and more congestive, which is so-called the accumulation in this work. The accumulated species in the chamber also carried some energy which was absolutely lower than that of the plasma but non-negligibly high comparing to cold air. The carried energy may be emitted and traveled in the ambient gas until being partially/totally absorbed by other species for reionization or captured by the wall of chamber. In case of reionization, electrons scarcely could jump over more than one energy level due to the relatively low energy comparing to the hot plasma. As a result, in the visible spectrum, $\mathrm{H}_{\alpha}(656 \mathrm{~nm})$, who induces a red color on the retina, was the most liable to be emitted and thus was the most intensive among the selected three visible emission lines of hydrogen due to the lowest energy gap as illustrated in Fig. 3. Similar reddening course was also observed in case 3: the gas color was yellow in the first 30 minutes with $60 \%$ ventilation power and turned to red in 10 minutes after reducing the ventilation power from $60 \%$ to $20 \%$. However, case 2 (opened APS with $90 \%$ ventilation power) and case 4 (VPS) were found to be stable without visible change in the color of the ambient gas, i.e. the ambient gas was always normal white.
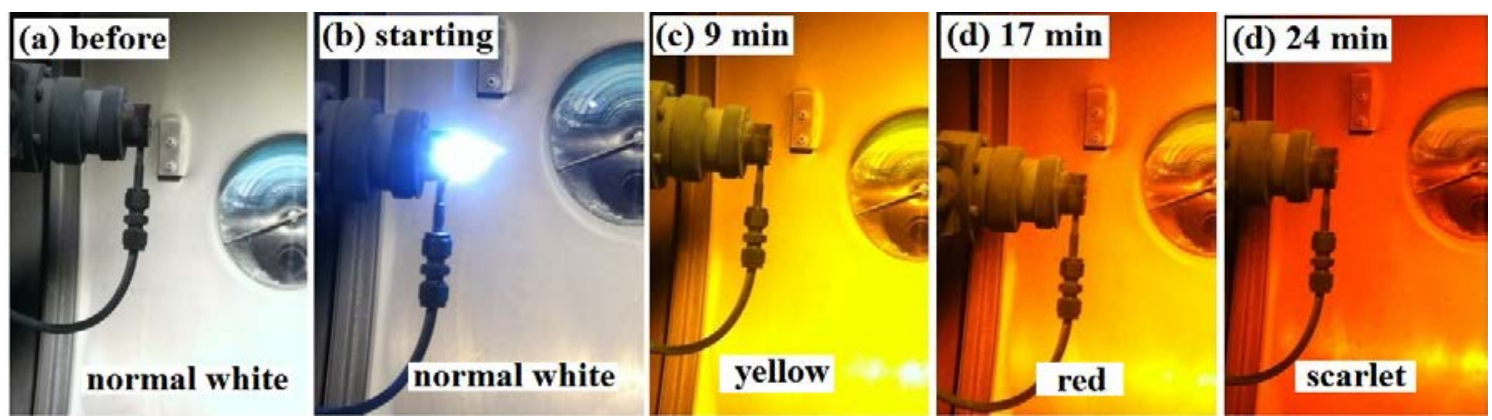

Figure 9 Color change of ambient gas inside the chamber with different operating time

In order to prove the reason of the reddening phenomenon, case 5 was carried out with the same operating parameters as case 1 except the exclusion of hydrogen. Photos of the ambient gas were equally captured as that of case 1 with temporarily stopping the plasma. Surprisingly, no visible change in color of the ambient gas was observed even after 30 minutes of the ignition (see Tab. 3); and the length of plasma jet was also stable. Accordingly, it can conclude that as the secondary gas of $\mathrm{Ar}-\mathrm{H}_{2}$ plasma hydrogen can turn the color of ambient gas to red with rate jointly determined by the ventilation power and the chamber volume; and the color darkened with time of plasma spraying which is most likely due to the increase in 
the concentration of hydrogen ions. It is also clear that longer time was needed to reach the scarlet color with stronger ventilation or within a bigger chamber.

Table 3 Color change of the ambient gas in each case

\begin{tabular}{cccccc}
\hline \multirow{2}{*}{ case } & \multicolumn{5}{c}{ color change of chamber gas } \\
& normal white & yellow & orange & red & scarlet \\
\hline 1 & 0 & 3 mins & 7 mins & 15 mins & 23 mins \\
2 & always & - & - & - & - \\
3 & 0 & 9 mins & 20 mins & 30 mins & - \\
4 & always & - & - & - & - \\
$\mathbf{5}$ & always & - & - & - & - \\
$\mathbf{6}$ & quickly reddened when closed, slowly faded when opened \\
\hline
\end{tabular}

\subsection{Effects of operating condition on ellipse of plasma jet}

Similarly, decrease in the length of the plasma jet was also observed by PFI with changing rates (see Tab. 4) determined by the operating conditions. The changing rates provided in Tab. 4 were approximately defined as the slope of the best fit curve of the major diameter and the minor diameter of the plasma jet. Thus, the closer to zero the changing rate, the more stable the plasma jet was, and vice versa. According to this, case 2 showed the best performance on the major diameter $\left(a \_l\right)$ with changing rate of -0.0004 which means a slight reduction of plasma length; and case 5 (closed APS, no ventilation, no $\mathrm{H}_{2}$ ) had the best performance on the minor diameter $\left(b \_l\right)$ with value of 0.0002 which presents an insignificant increase of the plasma width. In contrary, case 6(a) exhibited the biggest changing rate on the minor diameter with value of -0.064; while, case 6(e) performed the largest changing rate on the major diameter with value of -0.0826 .

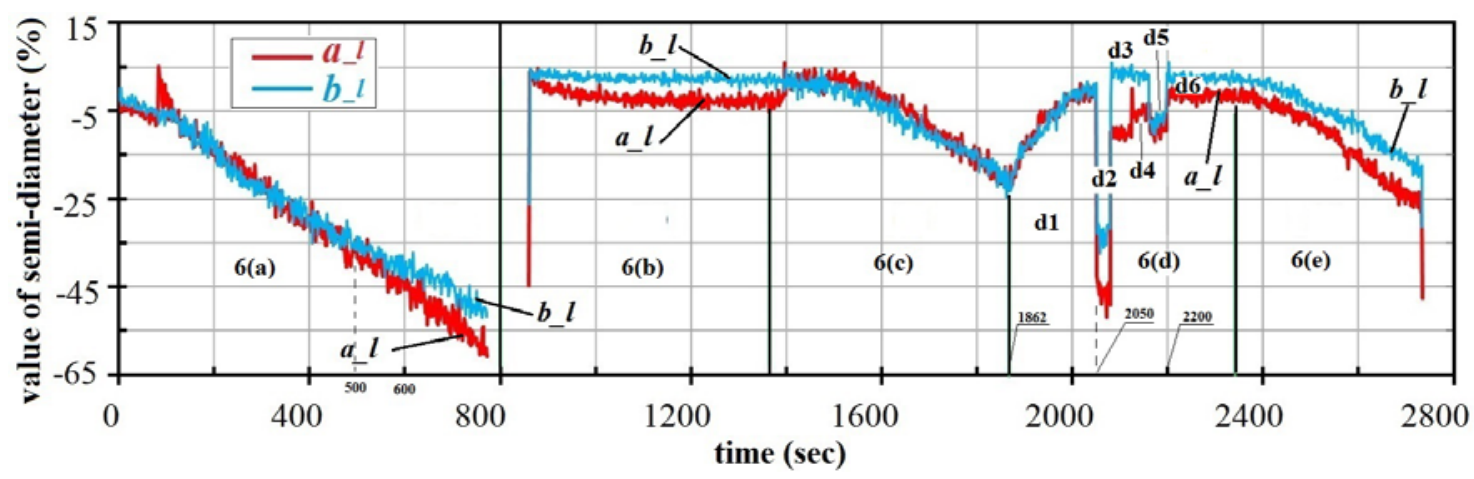

Figure 10 Variation of the left ellipse of case 6 in function of time 
Moreover, by glancing through Tab. 4, it can be found that case 2 (opened APS, 60\% ventilation power) showed smaller values of changing rate than that of case 4 (VPS) on both of the two diameters ( $a_{-} l$ and $b \_l$ ), which indicated that case 2 was closer to the perfect stable state. This also reveals the importance of different operating conditions on the stability of the plasma jet: chamber volume > pump power (ventilation and vacuum). Actually, by opening the sealing cover (case 2), the volume of the spraying chamber was equivalently enlarged, that the depleted gas needed much longer time to fill the volume up and thus the plasma jet was able to stay in stable. However, in VPS case the enclosed chamber was controlled by a vacuum pump which is much stronger than the ventilation pump; the volume of chamber was evidently smaller than that of the opened case. The depleted gas likely expelled the inside air quickly which resultantly induced a slight variation of plasma jet.

Table 4 PFI results in different cases

\begin{tabular}{|c|c|c|}
\hline \multirow{2}{*}{ case } & \multicolumn{2}{|c|}{ slope of decrease in left ellipse } \\
\hline & of $a \_l^{*}$ & of $b \_l^{*}$ \\
\hline 1 & -0.0279 & -0.0418 \\
\hline 2 & -0.0004 & -0.0007 \\
\hline 3 & $-0,0170$ & -0.0064 \\
\hline 4 & -0.0087 & 0.0009 \\
\hline 5 & 0.0016 & 0.0002 \\
\hline $6(\mathrm{a})$ & -0.0777 & -0.0640 \\
\hline 6(b) & -0.0059 & -0.0023 \\
\hline 6(c) & -0.0673 & -0.0558 \\
\hline 6(d) & 0.0157 & 0.0146 \\
\hline $6(\mathrm{e})$ & -0.0826 & -0.0616 \\
\hline
\end{tabular}

${ }^{1}$ : left ellipse means ellipse of plasma jet;

*: negative value means decrease, positive value means increase.

Additionally, the performance difference between case 1 and case 3 indicates that a strong ventilation power can efficiently stabilize the plasma jet. That with $60 \%$ ventilation power (case 3) the decreasing rate was -0.017 and -0.0064 for the major diameter and the minor diameter respectively; while without ventilation case 1 presented much higher decreasing rate with value of -0.0279 and -0.0418 for $a_{-} l$ and $b \_l$ respectively. Furthermore, concerning on the changing rate of case 1 and case 6(a), it significantly induces that even with similar operation the resultant changing rate of the plasma jet may be quite different, which was mostly due to the difference in the initial state of the chamber (humidity, temperature...) and was often assorted as an uncontrollable system error of plasma spray process. 
For better understanding the effect of operating condition on the stability of plasma jet, the PFI results of case 6 were graphically presented in Fig. 10 being divided into five zones corresponding to the operating procedures indicated in section 2.3. That in zone 6(a) and 6(e) the chamber was closed without ventilation; and in zone 6(c) the chamber was only opened with a gap of $5 \mathrm{~cm}$ between the sealing cover and the tank; while the chamber was completely opened to air in zone 6(b) and 6(d). Consequently, decreases of the major diameter and the minor diameter were detected in zone 6(a), 6(c) and 6(e) with different rates: in zone 6(a) 0.0777 and -0.064 for $a \_l$ and $b \_l$ respectively; in zone 6(c) -0.0673 and -0.0558 for $a \_l$ and $b \_l$ respectively; in zone 6(e) -0.0826 and -0.0616 for $a \_l$ and $b \_l$ respectively. It is apparent that zone 6(a) and zone 6(e) exhibited comparable decreasing rate of the major diameter and of the minor diameter due to the similar operating conditions; and zone 6(c) showed a moderate decreasing rate owing to the opening gap. Moreover, the decreasing rate of the two diameters of the left ellipse was dramatically minimized by completely opening the sealing cover, as shown in zone 6(b) of Fig. 10. That the major diameter $\left(a \_l\right)$ was slightly reduced by $8 \%$ in about 500 seconds with a decreasing rate of -0.0059 (see Tab. 4); while the minor diameter $\left(b \_l\right)$ was almost in stable with a decreasing rate only about -0.0023 (see Tab. 4).

In addition, the initial state of the chamber also influences the plasma performance: zone 6(b) was operated as firstly opening the chamber and then switching on the plasma; whereas in subzone 6(d1) the chamber was opened without stopping the plasma. Resultantly, zone 6(b) was obviously much more stable than subzone 6(d1) which was actually considered as a recovering stage of the plasma jet from the extinction due to the accumulation of the depleted gas in zone 6(c).

Furthermore, the secondary gas hydrogen plays a key role to intensify the plasma. That in subzone $6(\mathrm{~d} 2)$ due to the lack of hydrogen, the values of major diameter and minor diameter dropped from $0 \%$ to $-50 \%$ and $-35 \%$ respectively. Then in subzone $6(\mathrm{~d} 3), 6(\mathrm{~d} 4), 6(\mathrm{~d} 5)$ and 6(d6) the flowrate of hydrogen was continuously adjusted to be $5 \mathrm{~L} / \mathrm{min}, 2 \mathrm{~L} / \mathrm{min}, 1 \mathrm{~L} / \mathrm{min}$ and $3 \mathrm{~L} / \mathrm{min}$ respectively that abruptly made the plots of the two diameters dramatically climb up or drop down and finally stay around $0 \%$ in subzone $6(\mathrm{e})$ which is commensurable with the performance in zone 6(b).

As mentioned above, it is therefore speculated that the length and width of the plasma jet varies with time and the varying rate is determined by operating conditions. Firstly, when the chamber was completely sealed from the atmosphere and without ventilation, the plasma jet decreased with the largest rate in both $a_{-} l$ and $b \_l$ with value of -0.0826 and -0.064 
respectively (see Tab. 4). Secondly, when the enclosed chamber was controlled by a ventilation system, the state of the plasma jet was then only determined by the ventilation power: a high enough power was able to quickly pump out the depleted gas and thus keep the plasma jet near stable; otherwise, decrease was presented in both $a \_l$ and $b \_l$ with changing rate linked to the ventilation power. Thirdly, in an opened chamber, diluted by the air the accumulation of the depleted gas in the spraying chamber was therefore limited at low level that the plasma jet stayed approximately in stable. Finally, the stability of the plasma jet was also sensitive to the fraction of hydrogen in the plasma gas: with hydrogen the major diameter and the minor diameter of the plasma ellipse immediately climbed up to some value which signifies an intensification of the plasma; while without hydrogen the left ellipse became small with decrease in both $a \_l$ and $b \_l$ which indicates a shrinkage of the plasma jet.

\subsection{Emission lines spectrum of the plasma jet}

According to the prior analysis, three visible emission lines in Balmer series of hydrogen have been chosen for the Ar- $\mathrm{H}_{2}$ plasma diagnosis [31, 37]. On the basis of the Bohr model, the wavelength of the emit line depends on the way how the electron recombines with the atom (see Fig. 2(c)), e.g., an electron trapped by the atom nucleus may emit energy $(\Delta E)$ of $13.5 \mathrm{eV}$ to be stable in the first orbit $(\mathrm{n}=1)$ and thus a line is emit with wavelength $(\lambda)$ of $91.2 \mathrm{~nm}$ (see Annex I) according to the equation $\Delta E=h c / \lambda$ [39]. It is obviously known that the more electrons trapped to the same orbit of the atoms, the more quantized energy will be emit, therefor the more intensive the emit lines are. In another word, the intensity of the emit lines indicates the transition possibility of the corresponding emissions, e.g. with intensity of 500000 (see Annex I), the possibility for an electron to drop from level 2 to level 1 is much higher than dropping from a higher level to level 1. Similarly, it also can infer that when the intensities of the emit lines are detected being varied the change of the plasma state theoretically is the only reasonable cause. For example, a reduction in electron temperature of plasma may strengthen the $\mathrm{H}_{\alpha}$ while weaken $\mathrm{H}_{\beta}$ and $\mathrm{H}_{\gamma}$, that means more electrons can scarcely jump to an orbit higher than level 2 after being excited. Therefore, it is possible to exactly know the state of the plasma jet online by measuring the intensities of the emission lines of hydrogen. As detailed in Fig. 11, in Ar- $\mathrm{H}_{2}$ plasma the typical plasma emission spectrum is a combination of hydrogen emission lines and argon emission lines which are identified according to the Atomic Spectra Database of NIST (The National Institute of Standards and Technology, USA) [39]. 


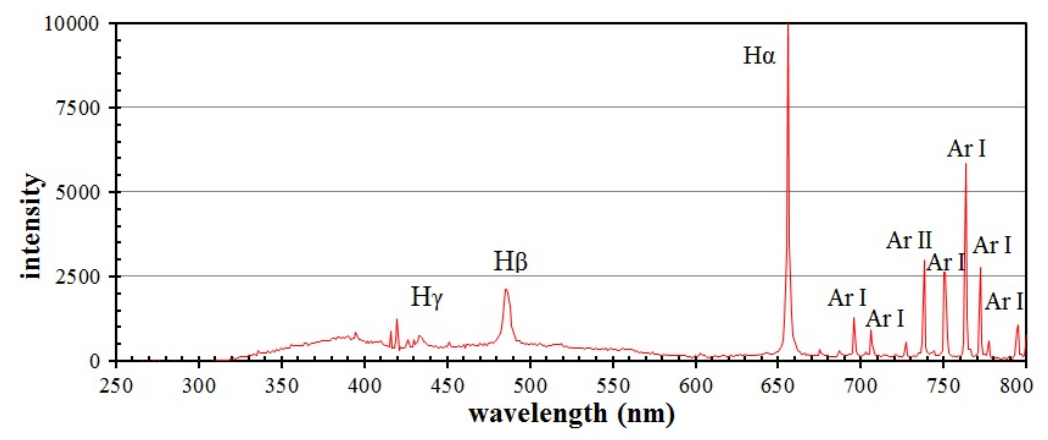

Figure 11 Typical emission spectrum of Ar- $\mathrm{H}_{2}$ plasma in range of $250 \mathrm{~nm} \sim 800 \mathrm{~nm}$

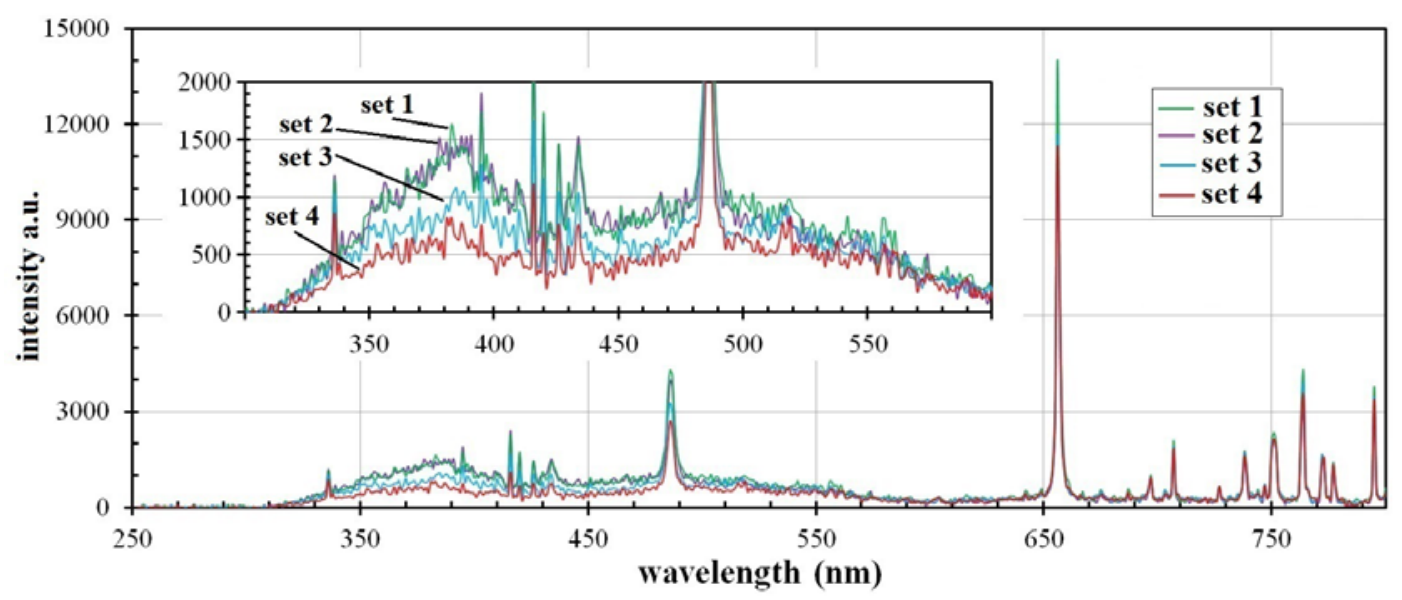

Figure 12 Behavior of emission light spectrum of plasma plume at different operating time

In parallel, a hill-like shape is presented in the range between $300 \mathrm{~nm}$ and $600 \mathrm{~nm}$ which is possibly a merged distribution of the weak argon emissions and the reported emissions in the range of $220 \mathrm{~nm}-440 \mathrm{~nm}$ due to the dissociation of $\mathrm{H}$ atoms [40, 41]. Because of the indistinguishable intensities, it is impossible to discern the effective signals from the hill-like shape; and resultantly most emission lines located in this range are unsuitable for the diagnosis purpose except lines with intensity obviously sticking out of the hill-like shape, e.g. $\mathrm{H}_{\beta}$ and $\mathrm{H}_{\gamma}$. However, the hill-like shape will give significant trace about the variation of plasma jet. As shown in Fig. 12 four sets of the plasma spectrum of case 1 are presented with heed on the hill-like region. The four sets were obtained at different times in scanning mode which is designed for detecting any possible variation in plasma jet. That set 1 was captured at the beginning of the process (case 1 ); set 2 was obtained at the $100^{\text {th }}$ seconds; set 3 was 
collected at the $300^{\text {th }}$ second; and set 4 was gained after 8 minutes. It is known from Fig. 12 that there was no big difference between set 1 and set 2. But after 300 seconds, the intensity of the hill-like region of set 3 was obviously lower than that of set 1 , especially in the range of $350 \mathrm{~nm}-500 \mathrm{~nm}$ that the maximal reduction was about 500 at $380 \mathrm{~nm}$. Moreover, set 4 was continuously lessened with reduced intensity around 500 .

When concentrating on hydrogen, change of the emission intensity is also able to be observed between sets in Fig. 12. That for $\mathrm{H}_{\gamma}(434 \mathrm{~nm})$, the intensity slowly dropped from 1522 of set 1 to 1450 of set 2 , then to 1037 of set 3 , and finally to 762 of set 4 ; similarly, the intensity of $\mathrm{H}_{\beta}$ firstly decreased from 4290 of set 1 to 3972 of set 2, then fell down to 3263 and 2720 of set 3 and set 4 respectively; but for $\mathrm{H}_{\alpha}$, the intensity firstly quickly increased from 11229 of set 1 to 13961 of set 2, then slowly dropped to 11611 and 11240 of set 3 and set 4 respectively. Regarding the intensity variation of $\mathrm{H}_{\alpha}, \mathrm{H}_{\gamma}$ and $\mathrm{H}_{\beta}$ between these sets, a reduction in energy of the plasma jet can be inferred which tallies with the decrease in length of the plasma jet mentioned in section 3.2.

In addition, more details about the intensity of hydrogen emission lines were presented in Tab. 5 with values measured at different time as indicated in Tab. 2; while Fig. 13 gives more intuitive depiction about the change of the emission intensity of $\mathrm{H}_{\alpha}, \mathrm{H}_{\beta}$ and $\mathrm{H}_{\gamma}$ with time order indicated by arrows. With Fig. 13 three important details can be reached: the first is the position of data point which signifies the emission intensity; then the second is the time order between data points which gives the tendency of change; and finally the third is the length of the trace which means the magnitude of the variation. As shown in Fig. 13 (a), (b) and (c), all data points of case 4 obviously outstood from others with higher vertical position, which means the strongest emission of $\mathrm{H}_{\alpha}, \mathrm{H}_{\beta}$ and $\mathrm{H}_{\gamma}$. However, a moderate decrease was observed in the intensity of $\mathrm{H}_{\beta}$ and $\mathrm{H}_{\gamma}$, especially between the first two points; while $\mathrm{H}_{\alpha}$ was found to be slightly reduced and stable at 1800 until the end of the process, which was most probably induced by the increase of chamber pressure due to the unbalance of gas flow between the vacuum pump (gas outlet) and the plasma gas (gas inlet). Without obvious change in emission intensity between the last three points, case 4 was considered being in balance state after 30 minutes of the ignition. As shown in Fig. 13, the last three filled-circular marks almost occupied the same position. 
Table 5 variation of the emission intensity of hydrogen

\begin{tabular}{cccccc}
\hline \multirow{2}{*}{ case } & \multicolumn{5}{c}{ emission intensity $\left(\mathrm{H}_{\alpha}: \mathrm{H}_{\beta}: \mathrm{H}_{\gamma}\right)(\mathrm{x} 10000)$} \\
& beginning & value 1 & value 2 & value 3 & value 4 \\
\hline 1 & $1.77: 0.40: 0.15$ & $2.07: 0.34: 0.12$ & $2.07: 0.34: 0.09$ & $2.03: 0.22: 0.05$ & $2.04: 0.14: 0.03$ \\
2 & $1.89: 0.42: 0.16$ & $1.89: 0.42: 0.16$ & $1.94: 0.44: 0.16$ & $1.95: 0.44: 0.16$ & $1.86: 0.42: 0.16$ \\
3 & $1.92: 0.43: 0.16$ & $2.10: 0.42: 0.15$ & $2.22: 0.43: 0.15$ & $2.32: 0.45 .0 .15$ & $2.42: 0.44: 0.14$ \\
4 & $1.48: 2.24: 0.23$ & $1.46: 1.98: 0.19$ & $1.44: 1.88: 0.18$ & $1.45: 1.90: 0.18$ & $1.45: 1.87: 0.18$ \\
\hline
\end{tabular}
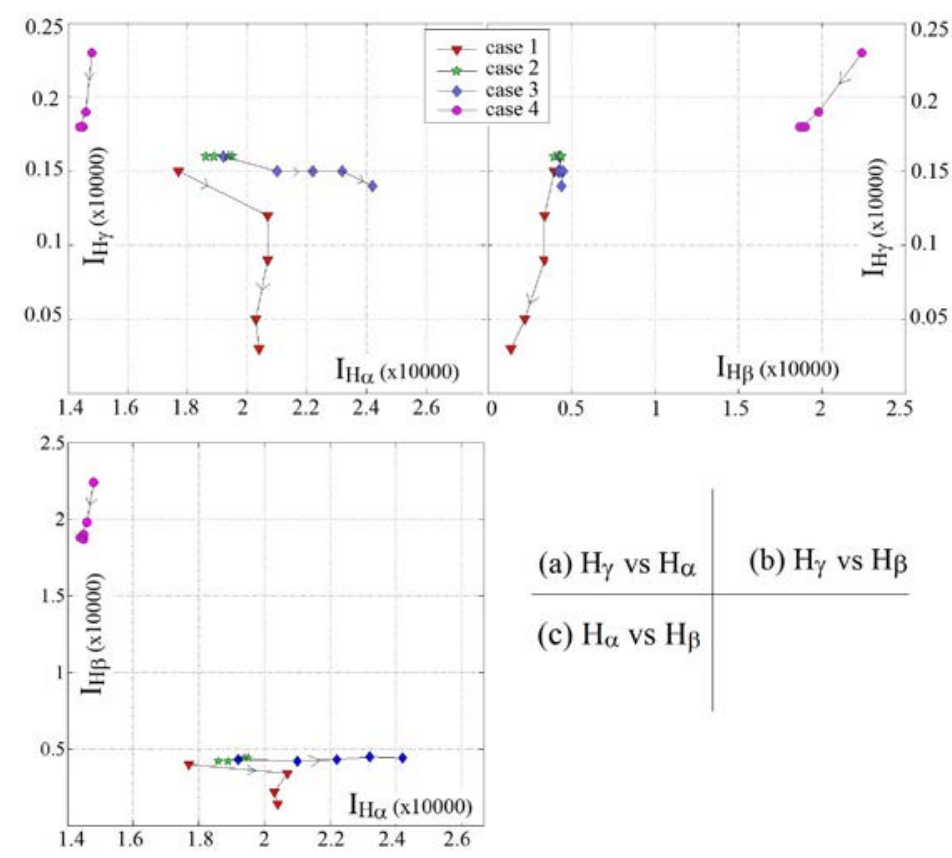

(c) $\mathrm{H}_{\alpha}$ vs $\mathrm{H}_{\beta}$

Figure 13 Map of detected emission intensity of Hydrogen

However, the situation in APS cases was quite different depending on the ventilation power and the spraying volume. As displayed in Fig. 13 the instability in case 1 is the strongest that the intensity of $\mathrm{H}_{\alpha}$ quickly increased from 17700 at the beginning to 20700 at the first value in 8 minutes and then stayed around 20400 until the end; however, $\mathrm{H}_{\gamma}$ was found to be rapidly dropping from 1500 at the beginning to 300 at the end and $\mathrm{H}_{\beta}$ was similarly reduced from 4000 at the beginning to 1400 at the end of the process. While on the base of case 1 , by increasing the ventilation power from $0 \%$ to $60 \%$, case 3 exhibited an obvious improvement of stability in $\mathrm{H}_{\beta}$ and $\mathrm{H}_{\gamma}$ accompanied by an increase of $\mathrm{H}_{\alpha}$ intensity from 19200 at the beginning to 24200 at the end in 40 minutes which agrees with the reddening phenomenon mentioned in section 3.2. It also can be found that with clustering distribution of the data points case 2 presented the best global stability in the three emission lines of hydrogen. 
Briefly, in VPS case both $\mathrm{H}_{\alpha}$ and $\mathrm{H}_{\beta}$ had much higher intensity than $\mathrm{H}_{\gamma}$; and $\mathrm{H}_{\beta}$ was stronger than $\mathrm{H}_{\mathrm{a}}$ in intensity. But in APS cases, $\mathrm{H}_{\alpha}$ was the strongest emitted line in intensity; and the decrease in intensity of $\mathrm{H}_{\beta}$ and $\mathrm{H}_{\gamma}$ meant the reduction in number of high energy state. Therefore, it can be concluded that with low ventilation power the energy of the plasma jet was gradually reduced accompanying the reddening phenomenon.

\subsection{Coating quality}

For all cases in Tab. 2, four samples were deposited at different time for estimating the effect of operating conditions on coating performance. For doing this coating weight was obtained as the difference of the substrate weight measured before and after the spraying. The average thickness was estimated from optical micrographs. Mean porosity ratio was evaluated over ten positions by image analyzing. The sample temperature and the sample-holder temperature in APS cases were measured with thermocouples.

\subsubsection{Coating weight}

In sight of coating weight, case 1, case 2 and case 3 had similar coating weight in the range of $0.8 \mathrm{~g}-1.2 \mathrm{~g}$; while case 4 (VPS) exhibited the highest performance (see Fig. 14) with a minimum of $1.44 \mathrm{~g}$ which was higher than the maximum of the APS cases. And the coating weight in VPS case presented a decreasing tendency from the first sample to the last sample with value of $2.12 \mathrm{~g}, 1.91 \mathrm{~g}, 1.96 \mathrm{~g}$ and $1.44 \mathrm{~g}$ respectively. Differently, for all APS cases, the coating weights slightly increased from the first sample to the second sample, and then kept stable between sample 2 and sample 3 which was subsequently followed by a slim decrease from sample 3 to sample 4 . 


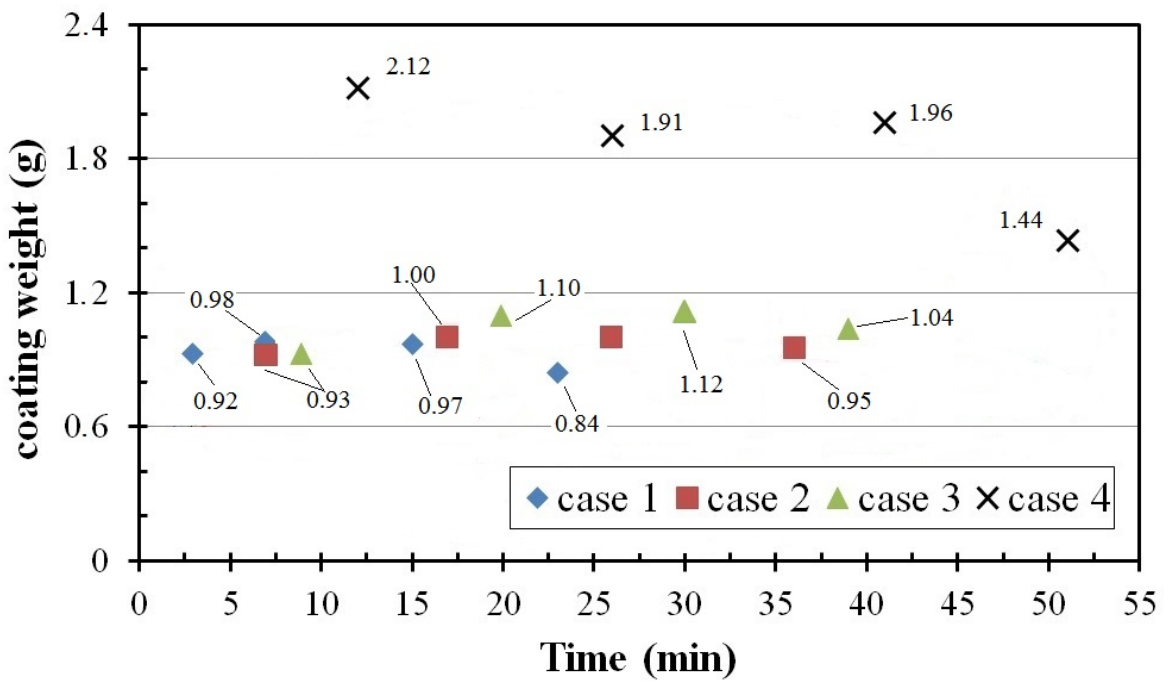

Figure 14 Plot of coating weights with time axis for case 1, case 2, case 3 and case 4

Coating weight is considered to be determined by the deposition efficiency which is further highly influenced by the particle state and the substrate state. In the present work, all substrates were prepared with the same procedure (clean, sandblast...), that the thermal difference was the only factor which could obviously affect the coating quality during the spraying. For understanding the behavior of the coating weight, two elements, which play a key role in determining the deposition efficiency [39], must be introduced: particle temperature and substrate temperature. Since suitable particle temperature and substrate temperature can highly enhance the adhesion between the flattened droplet and the substrate as well as the coating density.

As displayed in Fig. 14 the increase of the coating weight from sample 1 to sample 2 in the APS cases (case 1, case 2 and case 3) can be considered mainly coming from the preheating effect from the plasma jet as well as the thermal conduction of the substrate. As illustrated in Fig. 15, sample 1 was sprayed with a low starting temperature of the substrate, e.g. $36{ }^{\circ} \mathrm{C}$; while sample 2 was started at about $90{ }^{\circ} \mathrm{C}$. It is well known that for the YSZ-steel system a transition temperature has been proposed by M. Fukumoto [42] at $345 \mathrm{~K}$ which is higher than the starting temperature of the first sample in APS cases. Lower than the transition temperature, particles will be splashed into finger-like edge which entrains gas and restricts the thermal flux from the following hot particles. Owing to the preheating effect of plasma jet, the starting temperature of sample 2 was visibly higher than the transition temperature that consequently induced an increase of coating weight. Furthermore, once the transition temperature is reached or even exceeded by the substrate temperature, the preheating effect is 
no longer the major element to the deposition efficiency that no continuous augmentation of the coating weight was obtained with the increase of the starting temperature. Therefore, sample 2 and sample 3 were deposited with similar coating weight. Conversely, sample 4 was found with less coating than sample 3 which was probably resulted from the influence of ambient gas. According to the prior statement, with the reddening phenomenon and the decrease in length of the plasma jet the spraying chamber was gradually filled up by the depleted plasma gas. The temperature of the impacting particles was thus being reduced that some particles might be unable to be completely melted. In this case, even with preheating, the unmolten particles had no chance to be completely smoothly flattened and might be blown away from the substrate remaining pores or cracks.

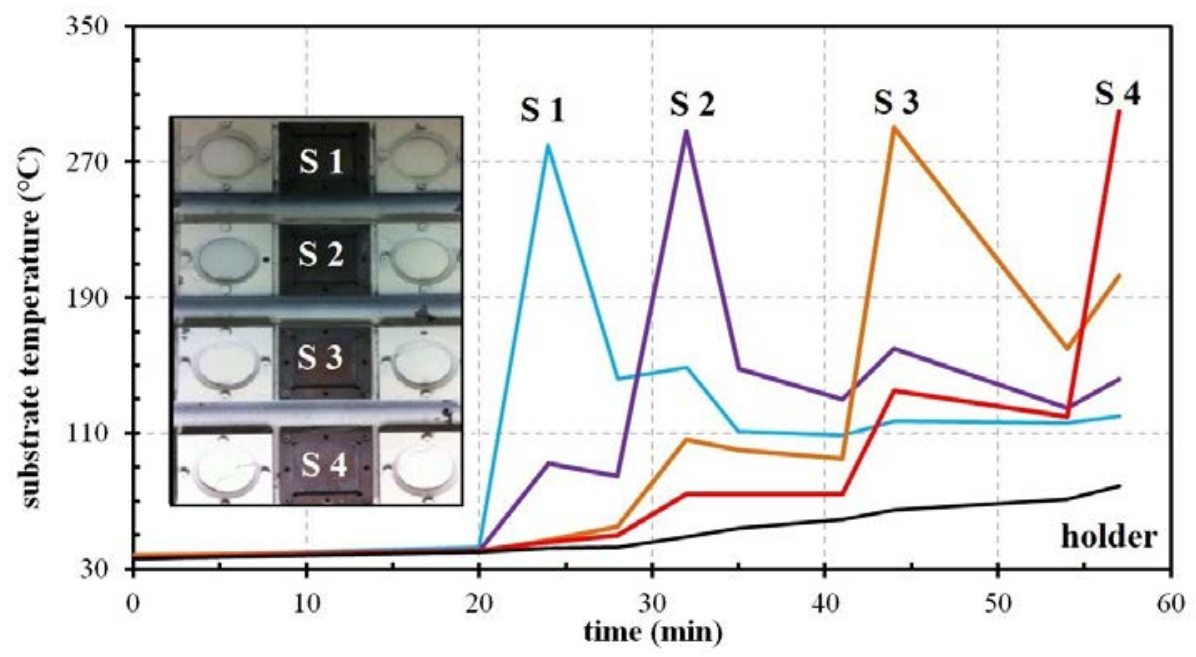

Figure 15 Plot of temperature variation of substrate in function of time due to the preheating effects of plasma flame and thermal conducting of sample holder

\subsubsection{Coating thickness and porosity ratio}

Thickness is also interesting for evaluating the effect of the operating conditions on the coating characteristics. As presented in Fig. 16, without clear trend to increase or decrease, VPS case exhibited much higher value of thickness than the APS cases. While in APS cases, evident trend existed between samples: in case 1 thickness slightly increased from $83 \mu \mathrm{m}$ of sample 1 to $89 \mu \mathrm{m}$ of sample 3, then sharply decreased to $67 \mu \mathrm{m}$ of sample 4 ; in case 2 coating thickness started from $84 \mu \mathrm{m}$ of the first sample then increased to $90 \mu \mathrm{m}$ and $91 \mu \mathrm{m}$ for sample 2 and sample 3 followed by a drop of $10 \mu \mathrm{m}$ to $81 \mu \mathrm{m}$ of sample 4 ; while, in case 3 thickness kept increasing from $79 \mu \mathrm{m}$ of sample 1 to $106 \mu \mathrm{m}$ of sample 4 . In parallel, a clear 
increase of thickness between different cases was found from sample 2 to sample 4 which was mainly driven by the jointly effect of the ventilation power and the chamber state (open/close). It indicates that powerful ventilation can help to increase the coating thickness; while opening the chamber brings negative effect.

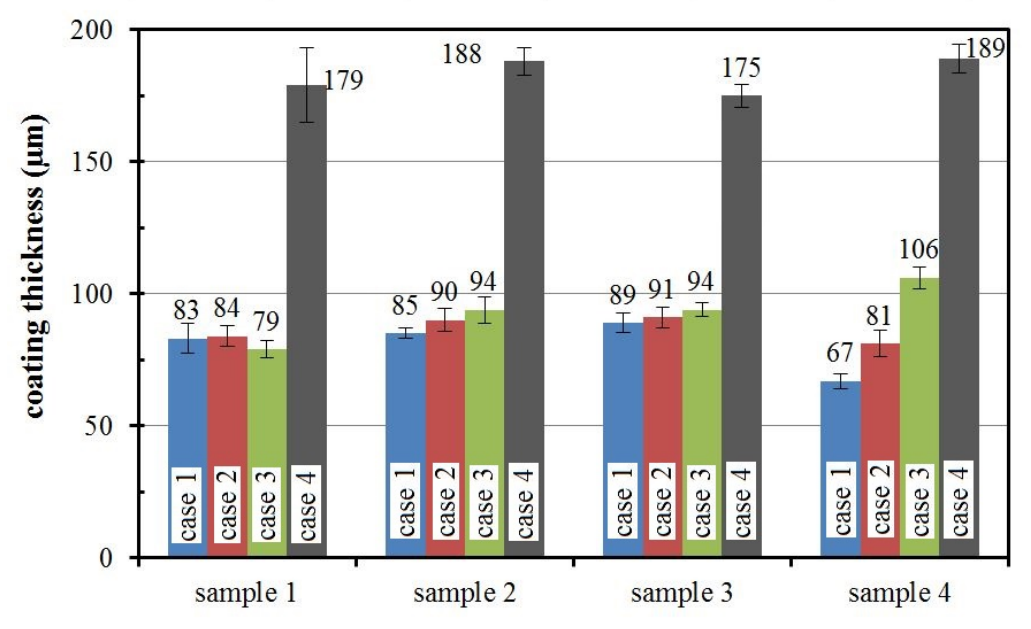

Figure 16 Thickness variations of coatings in different cases

Furthermore, the porosity ratio of coating is extremely important for revealing the effect of the operating conditions on the coating performance. As shown in Fig. 17, it's clear that each case exhibited a global increase from the first sample to the last sample. Firstly, in case 1 the porosity ratio started from $4.66 \%$ of sample 1 then dropped to the lowest value $4.46 \%$ of the second sample which was then followed by a small augmentation to $4.71 \%$ of sample 3 ; finally it jumped to $7.13 \%$ of sample 4 which was obtained at the $24^{\text {th }}$ minute. And then in case 3 , with the same operating conditions as case 1 but improving the ventilation power from 0 to $60 \%$, an obvious reduction in porosity ratio was obtained comparing with the samples in case 1. Regarding the position on the time axis, samples in case 3 showed moderate porosity ratio than that of samples in case 1 and case 2 . Moreover, by increasing the ventilation power to $90 \%$ and completely opening the chamber, it was found in case 2 that more pores were trapped in the coating comparing to the coatings in case 3. That the porosity ratio even climbed up to $7.18 \%$ after 35 minutes which was close to the value of the $4^{\text {th }}$ sample in case 1 . The Lowest porosity ratio was found as low as $2 \%$ in VPS case as the average value of the four samples with variance less than $0.5 \%$; cracks were nevertheless found to be deeply penetrating into the coating from the surface which brings drawback of VPS. Comparing the 
performances of the samples obtained at the similar time (sample 2 of case 1 vs sample 1 of case 2 and case 3, sample 3 of case 1 vs sample 2 of case 2 and case 3, sample 4 of case 1 vs sample 3 of case 2 and case 3), the reduction in porosity ratio indicated the positive effect of the ventilation power and the chamber state on the performance of coatings.

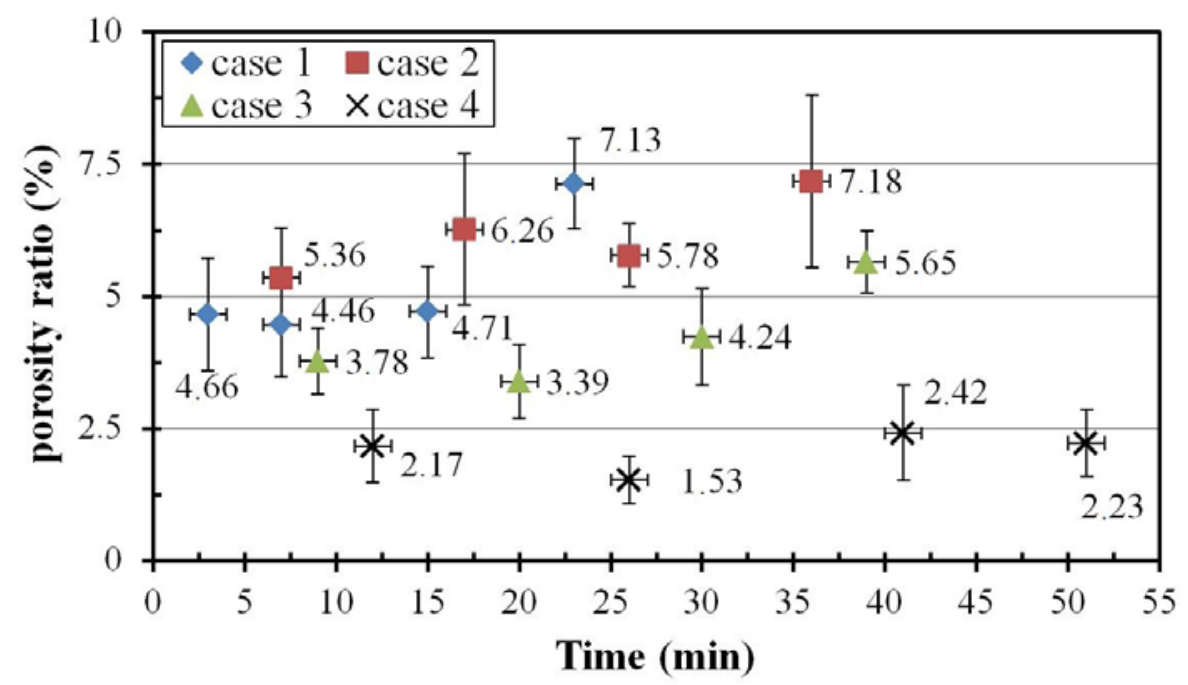

Figure 17 Plot of porosity ratios versus time for coatings in different cases

It has been reported that pores trapped in coating mainly came from the low impacting temperature of the in-flight particles and the low surface temperature of substrates [41]. In this work, all samples were fixed by the same sample-holder that meant substrates from different cases were fixed at the same position and experienced a similar thermal course. Therefore, the reason of the difference in coating characteristics mainly lay in the change of the impacting temperature of the in-flight particles. As mentioned in section 3.2 and 3.3, in APS cases the reddening phenomenon (see Tab. 3) and the shrinkage of the plasma jet (see Tab. 4) jointly induced the decrement of the impacting temperature of the in-flight particles which coincided with the increase of porosity ratio from sample 2 to sample 4 of case 1 , case 2 and case 3 . However, case 2 was different from other cases because of the contact with the atmosphere which continuously gave cooling effect on the plasma jet. Due to the design flaw of the ventilation system (see Fig. 2), heavy particles (feedstock and dust) in the ambient gas had less chance to be pumped out, and could be easily entrained into plasma jet. The heavy particles might be accelerated toward the substrates without being completely melted or even without being softened which could bring defects (pores, micro-gaps ...) into the coating. On 
the other hand, in case 3 all species released from the plasma jet were forced to follow the flow of the ambient gas due to the strong ventilation power that relieved the effect of the depleted gas on the ambient condition. Therefore, it can conclude that case 3 achieved the best performance among the APS cases.

\subsection{Reactions inside the plasma jet}

As mentioned in section 3.2, the addition of hydrogen in the plasma gas caused the accumulation of the depleted gas in the ambient gas and then induced the reddening phenomenon. The reason of the accumulation of the depleted gas was supposed to lie in the disequilibrium of the generation-consumption rate between ions and electrons of the excited hydrogen. Normally, in plasma jet, the hydrogen and argon are firstly ionized to different energy states forming numerous species depending on the energy density of the plasma, such as $\mathrm{H}^{+}, \mathrm{H}_{2}{ }^{+}, \mathrm{H}_{3}{ }^{+}, \mathrm{Ar}^{+}, \mathrm{ArH}^{+} \mathrm{Ar}^{2+}$ etc. [28, 40, 43-44]. And the exchange of charge and energy between these species is mainly in the form of elastic collision and radiation due to the high number density [44]; meanwhile reactions between these species are non-negligible. Moreover, it is worth to mention that most of the reactions are reversible and may shift toward different directions for achieving equilibrium while the reaction rate may be quite different. Voitsenya V. et al [45] have mentioned the coefficient $(\chi)$ of reactions about $\mathrm{H}_{3}{ }^{+}$at room temperature in $\mathrm{Ar}-\mathrm{H}_{2}$ plasma as below:

(1) $\mathrm{ArH}^{+}+\mathrm{H}_{2} \rightarrow \mathrm{H}_{3}^{+}+\mathrm{Ar}, \chi=5 \times 10^{-10} \mathrm{~cm}^{3}$ molecule $\mathrm{s}^{-1}$

(2) $\mathrm{H}_{2}^{+}+\mathrm{H}_{2} \rightarrow \mathrm{H}_{3}^{+}+\mathrm{H}, \chi=2.2 \times 10^{-9} \mathrm{~cm}^{3}$ molecule $\mathrm{s}^{-1}$.

(3) $\mathrm{H}_{3}^{+}+\mathrm{Ar} \rightarrow \mathrm{ArH}^{+}+\mathrm{H}_{2}, \chi=2 \times 10^{-10} \mathrm{~cm}^{3}$ molecule $\mathrm{s}^{-1}$.

Regarding the reacting coefficients of the above reactions, without proper ventilation, the accumulation of $\mathrm{H}_{3}{ }^{+}$in the plasma vessel can be foreseen to be strengthening with time. C.K Chen et al [28] and A. Bogaerts et al [40] have reported similar results that the number density of $\mathrm{H}_{3}{ }^{+}$is much higher than that of $\mathrm{H}^{+}$and $\mathrm{H}_{2}^{+}$in $\mathrm{Ar}-\mathrm{H}_{2}$ plasma. Consequently, reaction (3) is driven toward the right side to produce $\mathrm{ArH}^{+}$which can quickly consume free electron to subside down, $\mathrm{e}^{-}+\mathrm{ArH}^{+} \rightarrow \mathrm{Ar}+\mathrm{H}, \chi=2 \times 10^{-7} \mathrm{~cm}^{3}$ molecule ${ }^{-1} \mathrm{~s}^{-1}$ [45].In this work, high temperature plasma was generated, but the ambient gas nevertheless didn't deviate too much from the room temperature. That it is reasonable to refer to the coefficient of the reactions for better understanding the reddening of the ambient gas in this work which was 
mostly probably due to the accumulation of $\mathrm{H}_{3}{ }^{+}$. For verifying, three beakers of city water were placed at three different places in the chamber (see Fig. 18) and remained stationary overnight after case 5 . The $\mathrm{pH}$ strips showed that the reddened gas inside the chamber acidified the city water decreasing the $\mathrm{pH}$ value from 7 to the range of $1 \sim 3$ (see Fig. 18), that proves the existence of cations of hydrogen in the chamber after the spraying process. Similar tests have been carried out in other cases and the results indicated that the acidification only can be detected when the reddening phenomenon happens.

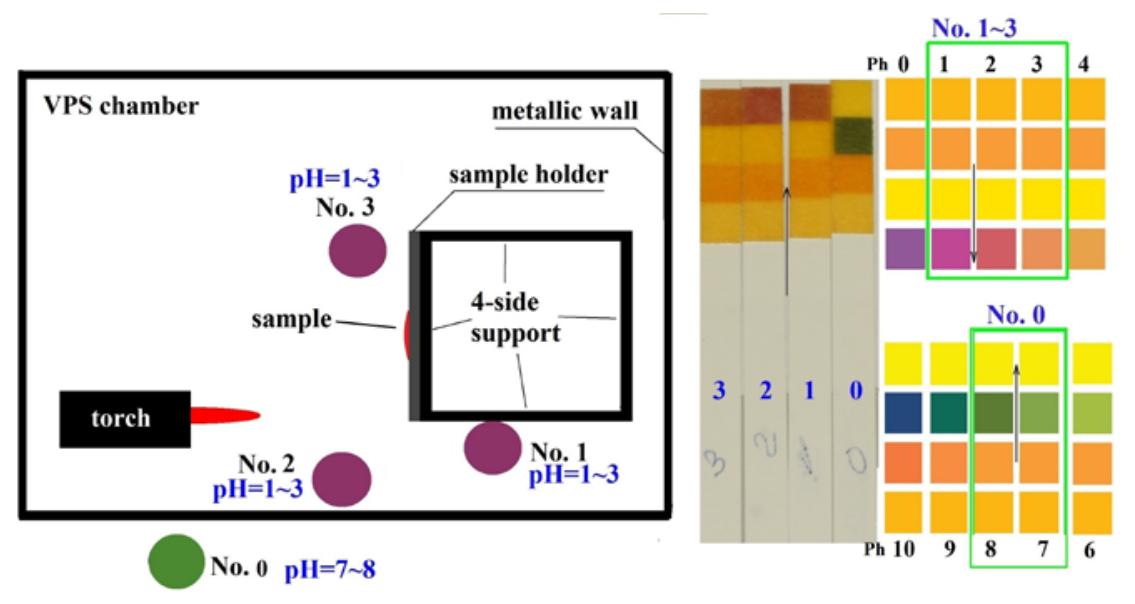

Figure 18 Illustration of $\mathrm{pH}$ strips test inside the chamber for case 1

Resultantly, it is clear now that when the chamber was filled by excited ions/atoms $\left(\mathrm{H}^{+}, \mathrm{H}_{2}{ }^{+}\right.$, $\mathrm{H}_{3}{ }^{+} \ldots$ ) the surrounding gas became more difficult to be re-ionized. The temperature of the plasma jet therefore gradually reduced as well as the length of the plasma jet. As a consequence, more and more electrons were unable to reach energy levels higher than 2 and thus the relative intensity of $\mathrm{H}_{\alpha}(656 \mathrm{~nm})$ kept increasing during the reddening of the ambient gas. The emission line with wavelength of $121 \mathrm{~nm}$ (emitted by dropping from level 2 to level 1) was the strongest radiation among all emission lines of hydrogen, but it was nevertheless out of the visible light spectrum and thus gave no effect on the ambient gas color. Moreover, in case of pure argon the plasma jet turned to be very stable without reddening phenomenon (case 5). According to the emission spectrum of argon, it is logical to consider that numerous lines were equally emitted during the recombination of electrons from different energy levels to the ground state and led to a normal white color. Resultantly, no color change has been watched in the case of pure argon plasma; no obvious change in the length of the plasma jet; 
yet, the plasma enthalpy turned to be lower as well as the plasma temperature. Thus to avoid the reddening phenomenon and the variation in plasma jet, strong ventilation is suggested to pump out the depleted gas and dust. And for environment protecting, the depleted gas shall be filtered to remove the acid component and dust before being exhausted to the atmosphere.

\section{Conclusions}

The effect of the ambient gas on the plasma jet and on the coating characteristics has been experimentally investigated by controlling the composition of the ambient gas though the sealing cover and the ventilation/vacuum pump. Reddening phenomenon of the ambient gas was watched in closed chamber with low ventilation power. The reddening rate was collaboratively dominated by ventilation power, hydrogen fraction and the chamber state (open/close). The reddened ambient gas was gradually fading when vacuum/ventilation pump starts to work or just keeping the chamber close for several hours. Meanwhile, obvious variations in the length and width of the plasma jet have been observed with changing rates decided by the operating conditions. As a result, the performance of coatings was being deteriorated which has been confirmed by the increase of the porosity ratio.

The results also indicated that the addition of hydrogen in the plasma gas caused the reddening of the ambient gas. That without hydrogen the plasma jet was very stable: no reddening was watched; no obvious variation of the plasma jet was detected; but unfortunately the plasma enthalpy was obviously lower. In case of hydrogen using, opening the chamber or executing high ventilation power or operating under vacuum can efficiently limit the reddening rate of the ambient gas and stabilize the plasma jet. Moreover, considering the acidifying effect of the reddened ambient gas on the city water, metal parts of the relative devices can be gradually eroded when water or moisture presented in the working site or in the exhausting system. More seriously, without proper treatment the reddened ambient gas exhausted to the atmosphere can bring severe environment problems or even cause critical physiological discomfort.

\section{Acknowledgments}

The authors would like to express thanks to Günter Roth and Ina Plock for their technical supports. The authors also would like to acknowledge financial support from DLR/DAAD 
Research Fellowship Program with No. 50019752 (Deutsche Forschungsanstalt für Luft- und Raumfahrt/Deutscher Akademischer Austausch Dienst).

Annex I hydrogen emission lights with different wavelength (nm)

\begin{tabular}{|c|c|c|c|c|c|c|c|}
\hline \multirow{2}{*}{$\mathbf{n}_{1} \backslash \mathbf{n}_{2}{ }^{\bar{\top}}$} & \multicolumn{7}{|c|}{$\mathbf{n}_{2}$} \\
\hline & 2 & 3 & 4 & 5 & 6 & 7 & $\infty$ \\
\hline $\mathbf{n}_{1}=1$ & 121.567 & 102.573 & $\begin{array}{l}97.252 \\
83000\end{array}$ & $\begin{array}{l}94.974 \\
33000\end{array}$ & 93.781 & $\begin{array}{c}93.075 \\
5600\end{array}$ & 91.2 \\
\hline $\mathbf{n}_{\mathbf{1}}=2$ & & $\begin{array}{l}\mathbf{6 5 6 . 2 7 0}^{*} \\
500000^{+}\end{array}$ & $\begin{array}{l}\mathbf{4 8 6 . 1 3 3} \\
180000\end{array}$ & $\begin{array}{c}\text { 434.0470 } \\
90000\end{array}$ & $\begin{array}{c}410.1740 \\
70000\end{array}$ & $\begin{array}{c}397.0072 \\
30000\end{array}$ & 365 \\
\hline $\mathbf{n}_{\mathbf{1}}=3$ & & & $\begin{array}{c}1875.13 \\
51000\end{array}$ & $\begin{array}{c}1281.807 \\
32000\end{array}$ & $\begin{array}{c}1093.817 \\
14000\end{array}$ & $\begin{array}{c}1004.98 \\
13000\end{array}$ & 820 \\
\hline $\mathbf{n}_{1}=4$ & & & & $\begin{array}{c}4052.279 \\
11000\end{array}$ & $\begin{array}{c}2625.871 \\
9000\end{array}$ & $\begin{array}{c}2166.118 \\
8000\end{array}$ & 1458 \\
\hline $\mathbf{n}_{1}=5$ & & & & & $\begin{array}{c}7459.90 \\
-\end{array}$ & $\begin{array}{c}4653.78 \\
4200\end{array}$ & 2280 \\
\hline $\mathbf{n}_{\mathbf{1}}=6$ & & & & & & $\begin{array}{c}12387.15 \\
340\end{array}$ & 3280 \\
\hline $\mathbf{n}_{\mathbf{1}}=7$ & & & & & & & 4400 \\
\hline
\end{tabular}

$\overline{\mathbf{T}}$ : means electron drops from $\mathrm{n}_{2}$ state to $\mathrm{n}_{1}$ state;

*: wavelength of emission light, $\mathrm{nm}$;

+ : relative intensity.

\section{References}

[1] Fauchais P (2004) Journal of Physics D: Applied Physics 37: R86-R108

[2] Pfender E (1999) PLASMA CHEM PLASMA P 19(1): 1-31

[3] Saremi M, Valefi Z, Abaeian N (2013) SURF COAT TECH 221:133-141

[4] Kim J, Dunn M G, Baran A J, Wade D P, Tremba E L (2008) J ENG GAS TURB POWER 115(3): 641-651

[5] Aruna S T, Sanjeeviraja C, Balaji N, Manikandanath N T (2013) SURF COAT TECH 219:131-138

[6] Grundmeier G, Stratmann M (1999) APPL SURF SCI 141:43-56

[7] Thirumalaikumarasamy D, Shanmugam K, Balasubramanian V (2014) Journal of Asian Ceramic Societies, 2014, 2(4): 403-415

[8] Wei S, Xu B, Wang H, Jin G, Lv H (2007) SURF COAT TECH 201(15): 6768-6771

[9] Shi S, Zheng Q, Fu G, Wang X (2004) NUCL ENG DES 231(1): 121-126

[10] Wu H, Jin Y, Nicoll A R, Barbezat G (1994) WEAR 176(1): 49-60

[11] Fleury H, Lee S M, Kim J S, Kim D H, Kim W T, Ahn H S (2002) WEAR 253(9-10): 1057-1069

[12] Fauchais P., Vardelle M, Vardelle A, Bianchi L (1996) CERAM INT 22(4):295-303 
[13] Kanta A F, Montavon G, Berndt C C, Planche M P, Coddet C (2011) EXPERT SYST APPL 38(1):260-271

[14] Guessasma S, Montavon G, Gougeon P, Coddet C (2003) MATER DESIGN 24(7):497502

[15] Kang J, Xu B, Wang H, Wang C (2013) Physics Procedia 50: 169-176

[16] Fauchais P, Vardelle A, Dussoubs B (2001) J THERM SPRAY TECHN 10(1): 44-66

[17] Kriba I, Djebaili A (2009) APPL SURF SCI 255(10): 5637-5640

[18] Coudert J F, Planche M P, Fauchais P (1996) PLASMA CHEM PLASMA P 16(1): 211s$227 \mathrm{~s}$

[19] Bisson J F, Gauthier B, Moreau C (2003) J THERM SPRAY TECHN 12(1): 38-43

[20] Heberlei J V (2002) HIGH TEMP MATER PROC 6(3):321-338

[21] Szente R N, Munz R J, Drouet M G (1992) PLASMA CHEM PLASMA P 12(3):327-343

[22] Rigot D, Delluc G, Pateyron B, Coudert J F, Fauchais P, Wigren J (2003) HIGH TEMP MATER PROC 7(2):175-185

[23] Xiong H, Zheng L, Sampath S, Williamson R L, Fincke J R (2004) INT J HEAT MASS TRAN 47(24): 5189-5200

[24] Liu T, Planche M P, Kanta A F, Deng S, Montavon G, Deng K and Ren Z M (2013) PLASMA CHEM PLASMA P 33(5): 1025-1041

[25] Cheng K, Chen X (2004) INT J HEAT MASS TRAN 47(23): 5139-5148

[26] Williamson R L, Fincke J R, Crawford D M, Snyder S C, Swank W D, Haggard D C (2003) INT J HEAT MASS TRAN 46(22): 4215-4228

[27] Spores R, Pfender E (1989) SURF COAT TECH 37(3): 251-270

[28] Chen C, Wei T, Collins L R, Phillips J (1999) Journal of Physic D: Apply Physic 32: 688-698

[29] Garcia M C, Rodero A, sola A, Gamero A (2000) SPECTROCHIM ACTA B 55: 17331745

[30] Mills R L, Ray P (2002) NEW J PHYS 4: 22.1-22.17

[31] Radovanov S B, Olthoff J K, Van Brunt R J, Djurovic S (1995) J APPL PHYS 78(2): 746-757

[32] Mills R L, Ray P, Dong J, Nansteel M, Dhandapani B, He J (2003) VIB SPECTROSC 31(2): 195-213

[33] Kühn G, Kock M (2006) Journal of Physic D: Apply Physic 39: 2401-2414

[34] Fauchais P, Coudert J F, Vardelle M, Vardelle A, Denoirjean A (1992) J THERM SPRAY TECHN 1(2): 117-128

[35] Zierhut J, Pellkofer W, Sagel A, Haug T, Landes K D (2001) Thermal Spray: New Surfaces for a New Millennium. (ED.) Berndt C C, Khor K A, Lugscheider E F, published by ASM International, Materials Park, Ohio, USA, pp 787-790

[36] Liu T, Arnold J.(2016) SURF COAT TECH 286: 80-94

[37] Jin D, Yang Z, Tang P, Xiao K, Dai J (2009) VACUUM 83: 451-453

[38] Wünderlich D, Dietrich S, Fantz U (2009) J QUANT SPECTROSC RA 110: 62-71

[39] Database of the National Institute of Standards and Technology (NIST):

http://www.nist.gov/pml/data/asd.cfm

[40] Bogaerts A, Gijbels R (2002) PHYS REV E 65(5): 056402 1-15

[41] Argon emission lights (also from NIST): 
http://astro.u-strasbg.fr/ koppen/discharge/argon.txt

[42] Fukumoto M, Yamaguchi T, Yamada M, Yasui T (2007) J THERM SPRAY TECHN, 2007, 16(5-6): 905-912

[43] Kuraica M, Konjevic N (1994) Physica Scripta 50: 487-492

[44] Mendez I, Tanarro I, Herrero V J (2010) PHYS CHEM CHEM PHYS 12: 4239-4245

[45] Voitsenya V, Naidenkova D, Masuzaki S, Kubota Y, Sagara A and Yamazaki K (2006) J. PLASMA FUSION RES SERIES, 7: 114-117 